\title{
To Determine Preference of Shoulder Pain Management by General Physicians in Lahore
}

\author{
Journal of Medical Clinical Case Reports
}

Research Article

\section{SAEED TAJ DIN*, HAFIZ ADEEL KHALID} Associate professor, Orthopaedic surgery, Azra Naheed medical
College Lahore

Final year student, Physical Therapy, Superior University Lahore
*Correspondence author

\author{
SAEED TAJ DIN \\ Associate Professor \\ Orthopaedic surgery \\ Azra Naheed Medical College Lahore \\ Pakistan
}

Submitted : 25 Dec 2020 ; Published : 25 Jan 2021

\begin{abstract}
Objective: To determine the preference of general practitioners how they diagnose and treat the shoulder pain.

Methodology: Descriptive cross sectional study were carried out among general physicians of the Lahore. Total 268 physicians were enrolled in the study and only 221 physicians responded. Data was collected by convenient sampling technique and physician were inquired about different aspects (diagnosis, investigation, treatment and referral) of management of shoulder pain.

Results: Total 221 physicians participated in the study that included 133 male and 88 female physicians. Result showed 68 and 83 physician were confident in the diagnosis of glenohumeral osteoarthritis and rotator cuff tear respectively. The most recommended investigation was radiographs of affected joint. Study revealed that 58 physicians also refer the patients to the physiotherapists for management.

Conclusion: Results of this study showed the preference of general physician about the management of shoulder pain. They diagnosed the patients of rotator cuff tear and glenohumeral arthritis and as an investigation they mostly recommend the radiograph. Their patients were being improved with physiotherapy in addition to symptomatic treatments.
\end{abstract}

Keywords: Preference, Shoulder Pain, Physician, Lahore, Intra-articular Injection, Diagnosis, Investigation, Treatment, Referra Introduction

Shoulder pain is common in populations and its prevalence is high $(41.3 \%)$ in Lahore [1]. It is the third most common muscular pain. Its diagnosis based on the physical examination that differentiates between the most common causes such as adhesive capsulitis (AdhC) or frozen shoulder, tear of rotator cuff (RCT), glenohumeral dysfunction and osteoarthritis (OA) and acromioclavicular joint (ACJ) pathologies [2].

Rotator cuff muscles are functionally active and provide stability to the shoulder joint and also thereby allow the full range of motion (ROM) by moving the head of humerus in the glenoid cavity. Any tear or fragility of the rotator cuff muscles can cause the dislocation or instability and hence damaging other muscles specially the long head of biceps muscle. The diseases related to the supraspinatus tendon are frequently linked with the long head of the biceps tendon. Other cause of chronic shoulder pain is the adhesive capsulitis with large prevalence rates of more than $5.3 \%$ in the general target population [3].
Chronic periodic pain of shoulder in young athletes is a main reason for medical consultation. Such type of pain is common in sports that involve repetitive movements of shoulder joint and excessive overhead movements [4].

One study was conducted in the UK that revealed that general practitioners needs some investigations for shoulder pain management such as ultrasound, magnetic resonance imaging and radiographs [5]. Another study was conducted almost greater than 10 years ago that collected data from the medical centers and clinics. The information collected from the general physicians were based on their recommendations for investigations, diagnosis and treatment or referral decisions $[2]$.

Three studies were conducted on the management of shoulder pain and out of these three studies the results of one study revealed that there was a low rate or no improvement in the patient complaints (functional outcomes) after the physician 
diagnosis and counseling on the management of shoulder pain [6]. A systematic review reported in 2004 on the prognostic studies that included the shoulder pathologies. These studies included the six large standard and ten low standard studies that were mostly carried out in the hospital settings. This review reported with high evidence that severe intensity of pain was less complain in a small scale health care center populations and that middle class revealed less results in working people [7]. Physician thoughts about opioids, it was necessary to understand the varying types of opioids which were accessible. Small dose of codeine i.e. less then $(\leq 30 \mathrm{mg})$ had been continuously the most speedily distributed among the formulations [8].

A study showed the role of ultrasound by general physicians for making the correct diagnosis and the management of different conditions that were related or may cause shoulder pain [9]. Questionnaire is used in this study. There are number of benefits for the online data distribution because of low cost, convenient and equally effective for both respondents and for the investigators and also beneficial for data collection. The results to the online method between the general practitioners varying, almost from 1-40\%. Physician response was batter in online than the postal method. Therefore two ways were used in our study to get a response. First was postal method and the second was online email survey distribution procedure.

Similar studies were conducted in UK and we conducted this study because of high number of cases of shoulder pain in Pakistan are being managed by the general practitioners. No study has conducted yet here that why the knowledge gap exists in this study so we would add some innovation to the literature that it would solely address the differential diagnosis and the management protocol for the pathologies causing shoulder pain by general physician in Lahore.

Our aim to conduct this study was to assess how general physicians diagnose and treat the shoulder pain and which investigation they mostly preferred and which treatment they mostly used in their settings or wether they prefer to refer these patients to the physiotherapists or not.

\section{Literature Review}

Artus M, et al. conducted a cross sectional study in the different countries such as USA, Canada and Australia that revealed the a little bit confidence of the general physicians (GPs) when they were asked about different aspects of shoulder pain management such as diagnosis, treatment protocol and the frequent use of the investigations. After this study there were no such studies conducted in the USA. This study determined the preference about the diagnosis and treatment protocol of the shoulder pain by the general physicians in the UK. It concluded that general physicians in the UK preferred radiographs firstly and secondly blood tests of their patients to confirm the diagnosis related to shoulder pain diseases. General physicians also recommended that they refer their more than $70 \%$ patients with rotator cuff tear (RCT) and adhesive capsulitis to the physical therapist [2].
Filip Struyf, PhD1 at el conducted a systemic review. Results of this survey showed that the non-traumatic shoulder pain with acute and subacute complaints were the more important factors for the recovery of the patients according to their diagnostic criteria [3].

Josh Naunton at el carried out a cross sectional study to determine the latest treatment protocol of shoulder pain that may be due to the rotator cuff tear and this study was conducted in the Australia by the general physicians. The objective was to rule out the treatment protocol of general physicians for rotator cuff related pain (RCRP) of shoulder that would vary according to the time. The treatment recommended by the general physicians for rotator cuff related pain was frequent use of corticosteroids injections and ultrasound scan therapy. The clinical outcome obtained after 12 weeks use of medications, daily activity modification and exercise based plan [10].

Victoria Tzortziou Brown at el conducted a Controlled Trials to evaluate the results of standard treatment used in the primary health care centers by the general practitioners for the management of musculoskeletal related diseases. It revealed that general practitioners providing different treatment protocols with proper counseling resulted in better outcome. This proper counselling of the patients and positive behavior of general physicians lead to more satisfying results. They concluded that there should be more studies conducted to provide the success of such treatment plan and also improve the general physician behavior and patient outcome. Another systematic review showed prognostic factors which were recorded in primary, secondary and tertiary health care clinics for those patients who came with shoulder pain complaints. Physician should consider these prognostic factors during the treatment of patients with shoulder pain complain. The patients with acute and severe non traumatic pain should be examined on daily basis and their treatment plan should be changed if they have no positive response and still their acute symptoms exist [7].

A cohort study on psychological factors that were linked with the treatment for those people who came with shoulder pain complain. Associated psychological factors need simultaneous treatment or counseling for better outcomes [11]. Another randomised controlled trial performed to evaluate the use of ultrasound scan for the treatment of acute shoulder pain. The results showed that outcomes of ultrasound scan and outcomes in any primary care center without ultrasound scan were almost same [12].

An analytical study evaluated the goals of management protocol of chronic pain; it evaluated the satisfaction of patients and priorities of general physicians for treatment of shoulder pain. It also determined the association between physician and patient. $48 \%$ of patients showed their high priority was reduction in pain intensity. $22 \%$ thought diagnosis was more important for them. Whereas the first top priority for $41 \%$ physicians was to improve the patient symptoms. The medication with low side effects was their priority for $26 \%$ patients [13]. 
T. Helfen at el. conducted a study on the management of prehospital shoulder dislocation. The facilities that were needed for shoulder dislocation and the reduction procedure were not carried out in the pre hospital settings. The main objective of this study was to evaluate facilities provided, sufficient time, and the availability of pre hospital setting for shoulder reduction. In this study 70 patients were enrolled and shoulder reduction was done in 47 patients. 40 patients were symptoms free after reduction and 7 patients complained of post reduction neurological symptoms [14].

\section{Objective}

To determine the preference of general practitioners regarding diagnose and treatment of the shoulder pain.

\section{Rationale}

This study was conducted to assess how general physicians diagnose and treat the shoulder pain and to know their preference in investigation, treatment and referral to the physiotherapist. However this study would raise a question about impact of basic clinical skills and better decision making of general physicians regarding management of musculoskeletal disorders. The conclusion for the enhancement of medical training in clinical practice for general practitioners was integrative.

\section{Operational Definition}

Self-made questionnaire is used in this study. This questionnaire included the four part (diagnosis, investigation, treatment and referral). There were total 15 questions according to the Likert scale. Their outcome measurements were taken as $(1=$ confidently yes, 2=likely, $3=$ uncertain, $4=$ unlikely, $5=$ confident no). Validity of questionnaire obtained by seeking the opinion aid of experts through content validity index (cvi). The reliability of the questionnaire obtained by conducting a pilot study and calculating the value of cronbach's alpha $(\alpha)$.

\section{Materials and Methods}

\section{Study design}

Descriptive cross sectional study

Setting

Private clinics

Private hospitals

Government hospitals of Lahore

Study Population

General practitioner of Lahore

Duration of the Study

6 months from 1. 3. 20 to 30.8 .20

Sample Size

Sample size $=\frac{Z_{1-\alpha / 2}{ }^{2} p(1-p)}{d^{2}}$

Sample size calculate by above formula was 221 by applying following parameters

$\mathrm{Z}_{1-\alpha / 2}=1.96$ (Standard normal variate at 5\% type I error $(\mathrm{p}<0.05)$

$\mathrm{P}=0.60$ (Preference of plain radiographs for diagnosing $\mathrm{RCT}$ ) (15), $d=0.05$ (absolute error)

\section{Sampling Technique}

Convenient sampling techniques was used in this study. Eligibility Criteria

Inclusion

In this study the general practitioners with more than 1 years of practice, male and female practitioners and practitioners of urban and rural areas were included.

\section{Exclusion}

Those practitioners were excluded who had not attended the training Workshops regarding treatment of muskuloskeletal disorders.

\section{Data Collection Procedure}

The cross sectional descriptive study carried out in Lahore. 221 general practitioners were included in the study. Convenient sampling was done. The data was collected from different private clinics and hospitals and also from government hospitals after the approval from the concern person or department. Study duration was 6 month. In our study those practitioners were included who were specilized in msk and had practice experience 1 years or more than 1 year and those were excluded who just attend the workshops or online trainings.

\section{Ethical Consideration}

Study was conducted after the approval from ethical review board.

Informed consent was taken before gathering the data from the general practitioners.

Confidentiality of the practitioners was maintained.

General practitioners had given right to choose or denay the study.

\section{Statistical Procedure}

Data was analyzed by calculating the frequency, percentage, mean and standard deviations of different variables by the descriptive statistics. Data was analyzed by using the SPSS version 23 .

\section{Result}

In this study 221 physicians enrolled. Demographic data of participants

\begin{tabular}{|l|l|l|l|l|l|}
\hline $\begin{array}{l}\text { Age } \\
\text { (years) }\end{array}$ & $\begin{array}{l}\text { Total } \\
\text { participants }\end{array}$ & Minimum & Maximum & Mean & $\begin{array}{l}\text { Std. } \\
\text { deviation }\end{array}$ \\
\cline { 2 - 6 } & 221 & 25 & 70 & 34.68 & 6.301 \\
\hline
\end{tabular}

Table 1: Age

The Mean age of the participants was found $34.68( \pm 6.301)$ with minimum age of 25 years and maximum age of 70 years (table 1).

\begin{tabular}{|l|l|l|}
\hline Gender & $\begin{array}{l}\text { Frequency } \\
(\mathrm{n})\end{array}$ & Percent (\%) \\
\hline Male & 133 & 60.2 \\
\hline Female & 88 & 39.8 \\
\hline Total & 221 & 100.0 \\
\hline \multicolumn{3}{|c|}{ Table 2: Gender } \\
\hline
\end{tabular}


Out of 221 general practitioner male $133(60.2 \%)$ and female $88(39.8 \%)$ were participated in this study (table 2$)$.

\begin{tabular}{|l|l|l|l|l|l|}
\hline \multirow{2}{*}{ Experience duration } & Total participants & Minimum & Maximum & Mean & Std. deviation \\
\cline { 2 - 6 } & 221 & 1 & 40 & 6.83 & 4.942 \\
\hline
\end{tabular}

Table 3: Experience

We showed the experience duration of general practitioner in the following table (table 3 ). Minimum duration was found 1 year and maximum duration was 40 years with mean experience duration 6.83 .

\begin{tabular}{|l|l|l|l|l|l|}
\hline Questions & \multicolumn{3}{|l|}{ Response } & \multicolumn{2}{l|}{} \\
\cline { 2 - 6 } & Confident yes & Likely & Uncertain & Unlikely & Confident no \\
\cline { 2 - 6 } & $\mathrm{N}(\%)$ & $\mathrm{N}(\%)$ & $\mathrm{N}(\%)$ & $\mathrm{N}(\%)$ & $\mathrm{N}(\%)$ \\
\hline $\begin{array}{l}\text { Do you think GPs should perform intraarticular shoulder } \\
\text { injection? }\end{array}$ & $44(19.9)$ & $58(26.2)$ & $29(13.1)$ & $31(14.0)$ & $59(26.7)$ \\
\hline $\begin{array}{l}\text { Do you think GPs trained in MSK can manage the } \\
\text { shoulder pain? }\end{array}$ & $51(23.1)$ & $63(28.5)$ & $53(24.0)$ & $30(13.6)$ & $24(10.9)$ \\
\hline $\begin{array}{l}\text { Do you think GPs specialist in medicine can treat the } \\
\text { shoulder problems? }\end{array}$ & $37(16.7)$ & $40(18.1)$ & $55(24.9)$ & $52(23.5)$ & $37(16.7)$ \\
\hline
\end{tabular}

Table 4: Descriptive analysis of shoulder pain management by general physician

In our study 268 general practitioners were enrolled and only 221 practitioner responded. They were inquired about the different aspects of management of shoulder pain. Firstly they were inquired about the preferences of intraarticular injection in the treatment of shoulder pain. Majority 59(26.7\%) practitioner were not confident about the performance of intra articular injection. Almost 63(28.5\%) physician were confident that general practitioners trained in MSK can manage the shoulder pain (table 4).

\begin{tabular}{|c|c|c|c|c|c|c|}
\hline \multirow{7}{*}{$\begin{array}{l}\text { In which } \\
\text { condition do } \\
\text { you think a } \\
\text { GP can make a } \\
\text { decision better? }\end{array}$} & & $\begin{array}{l}\text { Rotator Cuff Tear } \\
\text { N }(\%)\end{array}$ & $\begin{array}{l}\text { Glenohumeral } \\
\text { Osteoarthritis } \\
\mathrm{N}(\%)\end{array}$ & $\begin{array}{l}\text { Adhesive } \\
\text { capsulitis } \\
\mathrm{N}(\%)\end{array}$ & $\begin{array}{l}\text { Acute RC tear } \\
\mathrm{N}(\%)\end{array}$ & $\begin{array}{l}\text { Referred neck pain } \\
\mathrm{N}(\%)\end{array}$ \\
\hline & Confident yes & $45(20.4)$ & $31(14.0)$ & $39(17.6)$ & $37(16.7)$ & $31(14.0)$ \\
\hline & Likely & $53(24.0)$ & $68(30.8)$ & $51(23.1)$ & $50(22.6)$ & $59(26.7)$ \\
\hline & Uncertain & $62(28.1)$ & $51(23.1)$ & $60(27.1)$ & $58(26.2)$ & $57(25.8)$ \\
\hline & Unlikely & $48(21.7)$ & $49(22.2)$ & $49(22.2)$ & $53(24.0)$ & $32(14.5)$ \\
\hline & Confident no & $13(5.9)$ & $22(10.0)$ & $22(10.0)$ & $23(10.4)$ & $42(19.0)$ \\
\hline & Total & $221(100.0)$ & $221(100.0)$ & $221(100.0)$ & $221(100.0)$ & $221(100.0)$ \\
\hline \multirow{6}{*}{$\begin{array}{l}\text { In which } \\
\text { condition you } \\
\text { can easily } \\
\text { diagnose? }\end{array}$} & Confident yes & $55(24.9)$ & $41(18.6)$ & $49(22.2)$ & $46(20.8)$ & $45(20.4)$ \\
\hline & Likely & $47(21.3)$ & $50(22.6)$ & $52(23.5)$ & $61(27.6)$ & $64(29.0)$ \\
\hline & Uncertain & $54(24.4)$ & $58(26.2)$ & $61(27.6)$ & $61(27.6)$ & $47(21.3)$ \\
\hline & Unlikely & $50(22.6)$ & $43(19.5)$ & $41(18.6)$ & $40(18.1)$ & $42(19.0)$ \\
\hline & Confident no & $15(6.8)$ & $29(13.1)$ & $18(8.1)$ & $13(5.9)$ & $23(10.4)$ \\
\hline & Total & $221(100.0)$ & $221(100.0)$ & $221(100.0)$ & $221(100.0)$ & $221(100.0)$ \\
\hline \multirow{6}{*}{$\begin{array}{l}\text { What do you } \\
\text { think which } \\
\text { condition is } \\
\text { most likely the } \\
\text { reason behind } \\
\text { the shoulder } \\
\text { pain? }\end{array}$} & Confident yes & $83(37.6)$ & $28(12.7)$ & $42(19.0)$ & $42(19.0)$ & $35(15.8)$ \\
\hline & Likely & $40(18.1)$ & $71(32.1)$ & $57(25.8)$ & $57(25.8)$ & $53(24.0)$ \\
\hline & Uncertain & $29(13.1)$ & $53(24.0)$ & $53(24.0)$ & $52(23.5)$ & $49(22.2)$ \\
\hline & Unlikely & $31(14.0)$ & $47(21.3)$ & $46(20.8)$ & $44(19.9)$ & $37(16.7)$ \\
\hline & Confident no & $38(17.2)$ & $22(10.0)$ & $23(10.4)$ & $26(11.8)$ & $47(21.3)$ \\
\hline & Total & $221(100.0)$ & $221(100.0)$ & $221(100.0)$ & $221(100.0)$ & $221(100.0)$ \\
\hline
\end{tabular}

Regarding diagnosis of the different conditions of the shoulder pain, 68(30.8\%) practitioner stated likely chance in the diagnosis of glenohumeral osteoarthritis, 83(37.6\%) practitioner stated that they were confident about the diagnosis of RCT (table 5).

J Medical Case Repo; $2021 \quad$ www.unisciencepub.com 


\begin{tabular}{|c|c|c|c|c|c|c|}
\hline \multirow{8}{*}{$\begin{array}{l}\text { Which } \\
\text { investigation } \\
\text { you will } \\
\text { recommend } \\
\text { to patients for } \\
\text { shoulder pain? }\end{array}$} & & x-ray N (\%) & Blood test N (\%) & Ultrasound N (\%) & MRI N (\%) & Ct- scan N (\%) \\
\hline & & & & & & \\
\hline & Confident yes & $74(33.5)$ & $46(20.8)$ & $43(19.5)$ & $42(19.0)$ & $44(19.9)$ \\
\hline & Likely & $46(20.8)$ & $50(22.6)$ & $50(22.6)$ & $42(19.0)$ & $33(14.9)$ \\
\hline & Uncertain & $50(22.6)$ & $53(24.0)$ & $60(27.1)$ & $60(27.1)$ & $50(22.6)$ \\
\hline & Unlikely & $30(13.6)$ & $48(21.7)$ & $41(18.6)$ & $48(21.7)$ & $53(24.0)$ \\
\hline & Confident no & $21(9.5)$ & 24(10.9) & $27(12.2)$ & $29(13.1)$ & $41(18.6)$ \\
\hline & Total & $221(100.0)$ & $221(100.0)$ & $221(100.0)$ & $221(100.0)$ & 221(100.0) \\
\hline \multirow{6}{*}{$\begin{array}{l}\text { Which } \\
\text { investigation } \\
\text { is helpful in } \\
\text { diagnosis? }\end{array}$} & Confident yes & $66(29.9)$ & $46(20.8)$ & $40(18.1)$ & $39(17.6)$ & $38(17.2)$ \\
\hline & Likely & $38(17.2)$ & $41(18.6)$ & $50(22.6)$ & $51(23.1)$ & $43(19.5)$ \\
\hline & Uncertain & $49(22.2)$ & $64(29.0)$ & $56(25.3)$ & $67(30.3)$ & $53(24.0)$ \\
\hline & Unlikely & $49(22.2)$ & $40(18.1)$ & $47(21.3)$ & $33(14.9)$ & $51(23.1)$ \\
\hline & Confident no & 19(8.6) & $30(13.6)$ & $28(12.7)$ & $31(14.0)$ & $36(16.3)$ \\
\hline & Total & $221(100.0)$ & $221(100.0)$ & $221(100.0)$ & $221(100.0)$ & $221(100.0)$ \\
\hline \multirow{6}{*}{$\begin{array}{l}\text { Which } \\
\text { investigation } \\
\text { is used most } \\
\text { commonly? }\end{array}$} & Confident yes & $65(29.4)$ & $59(26.7)$ & $46(20.8)$ & $43(19.5)$ & $36(16.3)$ \\
\hline & Likely & $49(22.2)$ & $52(23.5)$ & $62(28.1)$ & $63(28.5)$ & $51(23.1)$ \\
\hline & Uncertain & $43(19.5)$ & $58(26.2)$ & $49(22.2$ & $45(20.4)$ & $55(24.9)$ \\
\hline & Unlikely & $46(20.8)$ & $32(14.5)$ & $39(17.6)$ & $40(18.1)$ & $39(17.6)$ \\
\hline & Confident no & $18(8.1)$ & 19(8.6) & $25(11.3)$ & $30(13.6)$ & $40(18.1)$ \\
\hline & Total & $221(100.0)$ & $221(100.0)$ & $221(100.0)$ & $221(100.0)$ & $221(100.0)$ \\
\hline
\end{tabular}

Table 6: Investigation

Regarding investigations 74(33.5\%) general practitioners recommended the x-ray for shoulder pain. 66(29.9\%) were confident that the $\mathrm{x}$-ray was helpful in their diagnosis and the most commonly investigation selected was $\mathrm{x}$-ray by $65(29.4 \%)$ practitioners. Blood tests were the second most commonly used investigation by 59(26.7\%) general practitioners (table 6).

\begin{tabular}{|l|l|l|l|l|}
\hline & & Physiotherapy N (\%) & NSAIDS N (\%) & Corticosteroids injections N (\%) \\
\hline \multirow{4}{*}{$\begin{array}{l}\text { Which treatment you will } \\
\text { prescribe to your patient for } \\
\text { shoulder pain? }\end{array}$} & Confident yes & $61(27.6)$ & $35(15.8)$ & $37(16.7)$ \\
\cline { 2 - 5 } & Likely & $49(22.2)$ & $56(25.3)$ & $56(25.3)$ \\
\cline { 2 - 5 } & Uncertain & $31(14.0)$ & $51(23.1)$ & $49(22.2)$ \\
\cline { 2 - 5 } & Unlikely & $33(14.9)$ & $40(18.1)$ & $39(17.6)$ \\
\cline { 2 - 5 } & Confident no & $47(21.3)$ & $39(17.6)$ & $40(18.1)$ \\
\cline { 2 - 5 } & Total & $221(100.0)$ & $221(100.0)$ & $221(100.0)$ \\
\hline \multirow{2}{*}{$\begin{array}{l}\text { Which treatment has } \\
\text { the better effect in the } \\
\text { management of pain? }\end{array}$} & Confident yes & $74(33.5)$ & $47(21.3)$ & $55(24.9)$ \\
\cline { 2 - 5 } & Likely & $45(20.4)$ & $44(19.9)$ & $42(19.0)$ \\
\cline { 2 - 5 } & Uncertain & $39(17.6)$ & $56(25.3)$ & $44(19.9)$ \\
\cline { 2 - 5 } & Unlikely & $42(19.0)$ & $43(19.5)$ & $49(22.2)$ \\
\cline { 2 - 5 } & Confident no & $21(9.5)$ & $31(14.0)$ & $31(14.0)$ \\
\cline { 2 - 5 } & Total & $221(100.0)$ & $221(100.0)$ & $221(100.0)$ \\
\hline
\end{tabular}




\begin{tabular}{|l|l|l|l|l|}
\hline \multirow{2}{*}{$\begin{array}{l}\text { What do you think patients } \\
\text { will be satisfied for what kind } \\
\text { of treatment? }\end{array}$} & Confident yes & $56(25.3)$ & $43(19.5)$ & $51(23.1)$ \\
\cline { 2 - 5 } & Likely & $52(23.5)$ & $59(26.7)$ & $52(23.5)$ \\
\cline { 2 - 5 } & Uncertain & $52(23.5)$ & $38(17.2)$ & $58(26.2)$ \\
\cline { 2 - 5 } & Unlikely & $38(17.2)$ & $40(18.1)$ & $38(17.2)$ \\
\cline { 2 - 5 } & Confident no & $23(10.4)$ & $41(18.6)$ & $22(10.0)$ \\
\cline { 2 - 5 } & Total & $221(100.0)$ & $221(100.0)$ & $221(100.0)$ \\
\hline \multirow{4}{*}{$\begin{array}{l}\text { What do you think which } \\
\text { effects? }\end{array}$} & Confident yes & $68(30.8)$ & $39(17.6)$ & $48(21.7)$ \\
\cline { 2 - 5 } & Likely & $51(23.1)$ & $50(22.6)$ & $48(21.7)$ \\
\cline { 2 - 5 } & Uncertain & $51(23.1)$ & $64(29.0)$ & $54(24.4)$ \\
\cline { 2 - 5 } & Unlikely & $35(15.8)$ & $38(17.2)$ & $39(17.6)$ \\
\cline { 2 - 4 } & Confident no & $16(7.2)$ & $30(13.6)$ & $32(14.5)$ \\
\cline { 2 - 4 } & Total & $221(100.0)$ & $221(100.0)$ & $221(100.0)$ \\
\hline
\end{tabular}

Table 7: Treatment

Out of 221 practitioners $61(27.6 \%)$ advised physical therapy to their patient's for shoulder pain. $74(33.5 \%)$ practitioners were confident that physiotherapy had better effects in the management of shoulder pain. While $56(25.3 \%)$ practitioners were confident that their patients were satisfied with physiotherapy treatment (table 7).

\begin{tabular}{|l|l|l|l|l|}
\hline & & Physiotherapist N (\%) & Orthopedic N (\%) & Rheumatology N (\%) \\
\hline \multirow{4}{*}{$\begin{array}{l}\text { Where did you refer the } \\
\text { patient? }\end{array}$} & Confident yes & $49(22.2)$ & $46(20.8)$ & $41(18.6)$ \\
\cline { 2 - 5 } & Likely & $58(26.2)$ & $50(22.6)$ & $60(27.1)$ \\
\cline { 2 - 5 } & Uncertain & $48(21.7)$ & $56(25.3)$ & $47(21.3)$ \\
\cline { 2 - 5 } & Unlikely & $42(19.0)$ & $48(21.7)$ & $29(13.1)$ \\
\cline { 2 - 5 } & Confident no & $24(10.9)$ & $21(9.5)$ & $44(19.9)$ \\
\cline { 2 - 5 } $\begin{array}{l}\text { What do you think which } \\
\text { these patients? }\end{array}$ & Total & $221(100.0)$ & $221(100.0)$ & $221(100.0)$ \\
\cline { 2 - 5 } & Confident yes & $69(31.2)$ & $57(25.8)$ & $64(29.0)$ \\
\cline { 2 - 5 } & Likely & $46(20.8)$ & $51(23.1)$ & $57(25.8)$ \\
\cline { 2 - 5 } & Uncertain & $48(21.7)$ & $50(22.6)$ & $30(13.6)$ \\
\cline { 2 - 5 } & Unlikely & $42(19.0)$ & $37(16.7)$ & $33(14.9)$ \\
\cline { 2 - 4 } & Confident no & $16(7.2)$ & $26(11.8)$ & $37(16.7)$ \\
\cline { 2 - 4 } & Total & $221(100.0)$ & $221(100.0)$ & $221(100.0)$ \\
\hline
\end{tabular}

Table 8: Referral

The data showed that $58(26.2 \%)$ practitioners refer their patients to the physiotherapist. While $69(31.2 \%)$ practitioners thought that physiotherapist can treat these patients and about $57(25.8 \%)$ thought that an orthopaedic surgeon can manage these patients (table 8).

\section{Discussion}

This study conducted to determine the preference of general practitioners that how they diagnose and treat the shoulder pain. General practitioner were asked about different conditions of the shoulder leading its pain. The results showed different responses about the investigation, diagnosis, treatment, and referral. Mostly practitioner were confident about the diagnosis of RCT. They mostly used the x-ray investigation for shoulder pain. Moreover they were confident that physiotherapy had better effect in the management of shoulder pain and hence they referred their patients to the physiotherapist [15].

Most of the practitioner were not confident about the results of intra-articular injections. One study was conducted that revealed that out of five general physicians only one physician thought that he would be unskillful in executing the injection for musculoskeletal related pain. Most of the general physicians also referred their patients to the secondary care because they thought they had no such skills for the injections but on the other hand most of physician considered himself as much as skillful that they can give the intra-articular injections. The most important restriction that came across to the physicians is to carry out intra articular and the intra muscular injection that was due to the lack of clinical practice and training and most of them had no confidence on their clinical skills [16].

Another study that was conducted by the sports physicians that were the member of American medical society of sports medicine showed that the physicians of sports and medicine mostly recommend the corticosteroids injections of methylprednisolone and triamcinolone. The dosage of the 
corticosteroids injections vary according to the physician practice. Mostly general physician doses vary from $21 \mathrm{mg}$ to $40 \mathrm{mg}$ for all the injections of corticosteroids. They mostly used corticosteroids injection with the lidocaine which was the local anesthetic. And some of the physician uses the ropivacaine instead of lidocaine as a local anesthetic. The one interesting thing was that in this study that only one physician was executing the high dose more than $40 \mathrm{mg}$ of triamcinolone and methylprednisolone for the treatment of pain related to the bursa or joint [17].

The most commonly used investigation by the majority of the practitioners that they recommend to their patients was $\mathrm{x}$-ray and the second investigation was the blood test for shoulder pain. Another study showed that there were lack of awareness about the referral of patients that would guide the availability of other experts. The other investigations carried out are magnetic resonance imaging (MRI) and computed tomography (CT scan) which proved to be beneficial in $80 \%$ to $90 \%$ of the cases and confirm their diagnosis [18].

In this study majority of the practitioners prescribed the physiotherapy treatment for shoulder pain management and their patients were satisfied with physiotherapy treatment. But in contrast; another study was conducted that showed that the administration of corticosteroids injection were proved more beneficial than the physiotherapy alone in the management of shoulder pain with stiffness. Side effects in this study generally were found low but it was important for the doctors to be careful about the side effects of corticosteroids injection (such as triamcinolone) especially in females [19].

Combination of different treatments protocols proved to be more beneficial in the management of shoulder pain after the attack of stroke. These protocols included physical therapy, ultrasound, infrared, localized icing and intra-articular injections of steroids and local anesthetics [20].

In our study most of the general practitioners referred their patient to the physiotherapy and $25.8 \%$ practitioners referred to the orthopedic surgeons for shoulder pain treatment. Another study concluded that patients with shoulder pain in physical therapy clinics often showed the signs of sub acromial impingement disease. The treatment protocols usually used by the physical therapists for sub acromial impingement disease. However a little bit ratio of physical therapists that were using massage, tape and bracing maneuver. But most of the patients were also still receiving treatment plan even no benefit after 12 weeks. These patients should be referred to the general practitioner (GP) or an orthopedic surgeon. The conclusions from this survey was not much clear as they selected only one group of health care providers, the physical therapists [21].

Another study about referral and investigations of shoulder pain stated that frozen shoulder or adhesive capsulitis remained undiagnosed before those patients were referred to the orthopedic surgeon. Ultrasound scan or imaging were the most commonly investigations made. So when they treated once the diagnosis made according to the standard clinical guidelines then their patients came with significant clinical difference and the functional improvement [22]. So we concluded that general practitioners refer their patients to the physiotherapist and generally they recommend the x-ray for investigation. Their response showed that their patients with shoulder pain were satisfied with physiotherapy management.

\section{Conclusion}

This study concluded that general practitioners refer their patients to the physiotherapist and less likely they refer to the orthopedic surgeon. Generally they recommend the x-ray as primary investigation for diagnosis purpose and the second investigation were the blood tests. Our study showed that patients with shoulder pain were satisfied with physiotherapy as well. In severe cases general physicians prescribed the intraarticular injection for symptomatic relief of shoulder pain.

\section{Limitations and Recommendations}

- This study had some limitations because this data were collected just from Lahore.

- There should be a study that would be conducted in other cities to determine the preferences of general physicians.

- Time duration was limited.

- One study should be conducted to assess the basic clinical skills of physician regarding musculoskeletal disorders.

\section{References}

1. Inayat F, Ali NS, Shahid H, Younus F (2017) Prevalence and Determinants of Frozen Shoulder in Patients with Diabetes: A Single Center Experience from Pakistan. Cureus 9(8): e1544.

2. Artus M, van der Windt DA, Afolabi EK, Buchbinder R, Chesterton LS, Hall A, et al. (2017) Management of shoulder pain by UK general practitioners (GPs): a national survey. BMJ open 7(6): e015711.

3. Struyf F, Geraets J, Noten S, Meeus M, Nijs J (2016) A Multivariable Prediction Model for the Chronification of Non-traumatic Shoulder Pain: A Systematic Review. Pain physician 19(2): 1-10.

4. Patel DR, Breisach S (2017) Evaluation and management of shoulder pain in skeletally immature athletes. Transl Pediatr 6(3): 181-189.

5. Cook T, Minns Lowe C, Maybury M, Lewis JS (2018) Are corticosteroid injections more beneficial than anaesthetic injections alone in the management of rotator cuff-related shoulder pain? A systematic review. British Journal of Sports Medicine 52(8): 497.

6. Tzortziou Brown V, Underwood M, Mohamed N, Westwood O, Morrissey D (2016) Professional interventions for general practitioners on the management of musculoskeletal conditions. The Cochrane database of systematic reviews 2016(5): Cd007495.

7. Kooijman MK, Barten DJ, Swinkels IC, Kuijpers T, de Bakker D, Koes BW, et al (2015) Pain intensity, neck pain and longer duration of complaints predict poorer outcome 
in patients with shoulder pain--a systematic review. $B M C$ musculoskeletal disorders 16: 288.

8. 8. White R, Hayes C, Boyes AW, Chiu S, Paul CL (2019) General practitioners and management of chronic noncancer pain: a cross-sectional survey of influences on opioid deprescribing. J Pain Res 12: 467-475.

9. Allen GM (2018) The diagnosis and management of shoulder pain. $J$ Ultrason 18(74): 234-239.

10. Naunton J, Harrison C, Britt H, Haines T, Malliaras P (2020) General practice management of rotator cuff related shoulder pain: A reliance on ultrasound and injection guided care. PloS one 15(1): e0227688.

11. Chester R, Jerosch-Herold C, Lewis J, Shepstone L (2018) Psychological factors are associated with the outcome of physiotherapy for people with shoulder pain: a multicentre longitudinal cohort study. British Journal of Sports Medicine 52(4): 269-275.

12. Ottenheijm RPG, Cals JWL, Winkens B, Weijers RE, de Bie RA, Dinant G-J (2016) Ultrasound imaging to tailor the treatment of acute shoulder pain: a randomised controlled trial in general practice. BMJ open 6(11): $\mathrm{e} 011048$.

13. Henry SG, Bell RA, Fenton JJ, Kravitz RL (2017) Goals of Chronic Pain Management: Do Patients and Primary Care Physicians Agree and Does it Matter? Clin J Pain 33(11): 955-961.

14. Helfen T, Ockert B, Pozder P, Regauer M, Haasters F (2016) Management of prehospital shoulder dislocation: feasibility and need of reduction. European Journal of Trauma and Emergency Surgery 42(3): 357-362.

15. Artus M, van der Windt DA, Afolabi EK, Buchbinder R, Chesterton LS, Hall A, et al. (2017) Management of shoulder pain by UK general practitioners (GPs): a national survey. BMJ open 7(6).

16. Spruit E, Mol MF, Bos PK, Bierma-Zeinstra SMA, Krastman P, Runhaar J (2020) Self-Assessment of Competence and Referral Behavior for Musculoskeletal Injections among Dutch General Practitioners. Journal of Clinical Medicine 9(6): 1880.

17. Cushman DM, Teramoto M, Asay A, Clements ND, McCormick ZL. Corticosteroid and Local Anesthetic Use Trends for Large Joint and Bursa Injections: Results of a Survey of Sports Medicine Physicians. PM\&R.n/a(n/a).

18. Remedios D, Drinkwater K, Warwick R (2014) National audit of appropriate imaging. Clinical Radiology 69(10): 1039-1044.

19. van Windt DAWMd, Koes BW, Devillé W, Boeke AJP, de Jong BA, Bouter LM (1998) Effectiveness of corticosteroid injections versus physiotherapy for treatment of painful stiff shoulder in primary care: randomised trial. $B M J$ 317(7168): 1292-1296.

20. Walsh K (2001) Management of shoulder pain in patients with stroke. Postgraduate Medical Journal 77(912): 645649.

21. Karel YHJM, Scholten-Peeters GGM, Thoomes-de Graaf M, Duijn E, van Broekhoven JB, Koes BW, et al. (2017) Physiotherapy for patients with shoulder pain in primary care: a descriptive study of diagnostic- and therapeutic management. Physiotherapy 103(4): 369-378.
22. Cadogan A, Mohammed KD (2016) Shoulder pain in primary care: frozen shoulder. Journal of Primary Health Care 8(1): 44-51.
Copyright: C2021 SAEED TAJ DIN. This is an open-access article distributed under the terms of the Creative Commons Attribution License, which permits unrestricted use, distribution, and reproduction in anymedium, provided the original author and source are credited. 